\title{
Mobile Apps the Educational Solution for Autistic Students in Secondary Education
}

\author{
https://doi.org/10.3991/ijim.v13i02.9896 \\ Agathi Stathopoulou $(\bowtie)$ \\ agathi.stathopoulou@yahoo.com \\ Zoe Karabatzaki, Dimosthenis Tsiros \\ Ministry of Education, Athens, Greece \\ Spiridoula Katsantoni \\ Center for Diagnosis, Differentiation and Support, Athens, Greece \\ Athanasios Drigas \\ National Center for Scientific Research "Demokritos", Athens, Greece
}

\begin{abstract}
For many adolescents in developed countries mobile apps can be the easy way for learning and teaching. This paper examines its role in secondary education focusing in mobile applications that support autistic students. The results of a research revealed the educators 'views that high school students with autism may use mobile apps in a variety of supportive educational ways.
\end{abstract}

Keywords-Secondary education, autism, adolescents, mobile apps

\section{Introduction}

Our knowledge and understanding of academic success and failure, ability and disability can be considered as cultural constructions. This is because the dominant group in a society defines the features of the culture that differentiate 'those who can' and 'those who can' $t$ ' and cultural understandings of difference are reflected not only in the beliefs and attitudes of people, but also in the reactions and behaviour of individuals [1] and especially in the beliefs and attitudes of educators [2 ] .

Traditionally, education has been offered in classes where students can interact directly with their educators, making teachers physical presence basic teaching pylon [3]. Undoubtedly, in recent years the dominant culture of education has been oriented to computers causing substantial issues, mostly conflicts between informal learning with personal devices and traditional classroom education [4]. The wide distribution of computers and communication technologies has made every learning process easier. Since the arrival of mobile phones in the 1980s, they have been widely used by people of all ages all around the world. It could be said that the whole world is becoming mobile; mobile phones are not only communication devices, but also portable and private pieces of technological equipment [5]. Mobile learning represents a new 
technological trend that is ubiquitous in education, powerful, highly portable and endowed with multimedia capabilities bringing a new dimension to curriculum delivery [6]. There is great potential in using mobile devices to transform the way we learn by changing the traditional class- room to one that is more interactive, engaging and successful. Provided the possibility of teaching without being restricted by time and place, enabling learning to continue after class is over or outside the classroom in places where learning occurs naturally. Furthermore, provide the connection between educators and learners on a more personal level with digital devices that they use on a regular basis, while sensing technologies enable learning to be personalized and customized to the needs of individual learner [7].

Since then a new revolutionary approach of teaching with mobile devices equipment begins. Internet connections have created a way for a new form of electronic learning, called mobile learning, internet-enabled mobile devices can help students to access learning resources and online courses, anywhere and at any time [8].

In the last decade most adults and adolescents in developed countries use mobile phones and mobile devices, and for many people in developing countries a mobile device can be the easy way for long distance communication. Additionally, in a parallel educational development to the spread of personal technology, schools, colleges and universities have experimented with handheld technology for educational reasons, including classroom response practice, data probes, and digital assistant tools. Universities allow students to bring laptop computers to lectures and some schools are now providing pupils with tablet computers. As personal mobile technologies for learning become more widespread, studies are begging to show evidence of the value of incorporating mobile devices in teaching and learning [4]parallel with traditional ways of learning[9].

In these new conditions a new generation of educators is created who have been oriented in the rapid and analytical transmission of information and the easier understanding by students created. Digital learning is a flexible learning in a digital world. Flexible learning is the focus of a new wave of interest. There is more flexibility to meet the needs of the learner, through adaptability to different needs of the learner, learning patterns and settings, and media combinations. Indeed, it would appear that wherever one looks, institutions are rushing headlong to embrace the Knowledge Media and to adopt new, open and distant learning practices [10]

\section{Mobile Application in High and Secondary Education}

The last decade, we have observed an impressive increase in the use of mobile learning technologies especially in high schools globally. A new educational environment, has been created into the classroom with digital media. These devices have attracted interest, by the educational community mainly due to their versatile learning capabilities [11]. Every new version of these devices brings innovative features that make them more convenient and affordable, and new apps that make learning procedure easier become available continually. 
Mobile apps are increasingly becoming ubiquitous, penetrating and transforming everyday social views and practices. These practices can be accompanied with text documents in different formats, audiovisual contents with videos, applications, and social networks. Smartphones are no longer only a tool for communication, but in many cases have become an instrument of people's social and work life, and possibly, a powerful instrument in academic life. Therefore, middle and higher education in developed and developing countries are now trying to establish the use of smartphones in the learning process from different perspectives and teaching learning methods [13]. Mobile devices such as smartphones and tablets are gaining popularity due to their relatively strong computing capability built into small sizes and their internet connectivity. The possibility of various types and easy-to-use mobile software applications allows users to investigate alternative learning and communication methods. Mobile apps also are now gaining increasing role and popularity across educational research .It is estimated that by $2015,80 \%$ of people accessing the internet will do it through cell phones. Mobile technologies are now gaining increased attention and popularity across education sectors, which has led to innovation in mobile app design [14].

In addition, in the last decade a prevalence of mobile technologies among college students is estimated. In fact, the majority of students' smartphones and tablets are reportedly used for academic purposes. Furthermore, many educators in secondary schools emphasize in the creative, student-centered pedagogical approaches facilitated by mobile apps, while others stress the role of online communication and collaboration in creating well-informed and well-connected global citizens. The latest generation of smart phones has became tools for supporting learning — inside and outside the classroom .Mobile applications also have significant potential to be used in literacy performance and in mental health interventions with adolescents [15].

Undoubtedly, mobile apps provide the greatest possibility for effective integration of technological hardware into language learning. These devices are technologically superior to usual mobile phones, running on advanced operating systems such as iOS (Apple), Android (Google) and Symbian (Nokia) which allow the use of highresolution touch-screen interfaces and smartphone-specific applications [16] .Also, they are usually owned by the students themselves, at a relatively low-cost [17]. These mobile apps features mean that smartphones have the potential to become significant devices not only in language learning, but also in general the ability to learning ability access [18].

Mobile apps are rapidly growing in importance and can be used for various functions. They have been used widely especially in educational inquiry. One educational direction for which mobile apps were used was training to read and pronounce the verses of the Holy Quran. There are apps that offer students the opportunity to read and explain the Quran, and search for a particular word or phrase in the text as well as listening to verses of the Holy Quran. Recent study aimed to declare the relationship between the behavioral factors and perceived usefulness of using the mobile to revel application "Say Quran" for studying the Quran on students' perceived performance, satisfaction and behavior [19]. In this research, students of the Islamic University had been asked to use the apps to help them on study the Quran. The results from this 
study provide evidence that there is a positive relationship between the mobile application "Say Quran" and students' perceived performance, satisfaction and behavior while engaged in studying the Holy Quran [15].

The Spanish National University of Distance Education published a study regarding the benefits of smartphones in higher education. The ambition of this research was to assess the value of a specific didactic mobile application and the utility to enhance student learning in university issues in ubiquitous environments and develop universal competencies according to the European Higher Education Field [20]. The main aim of the study was to reveal and assess students' perceptions regarding the capabilities of smartphones and apps in improving learning processes in university subjects were assessed. The conclusions demonstrate that the use of apps developed specifically for university subjects is highly valued by students as a new format which equally supports and enhances learning practices that not only provide further opportunities to establish connections and relations with their subjects, but also foster collaborative work among students and professors.

To underline collaboration and support real world skills, universities are experimenting with digital education policies that allow for more flexibility in interactions between students when working on projects and assessments [21]. In this context, many Universities around the world have begun implementing mobile learning with smartphones. For example, students at the University of Phoenix study in over 200 institutions simultaneously as well as online. With the university's mobile app, students can view their course materials, flag and mark posts even when they are offline, and participate in class discussions, gaining required participation points out of anywhere. In addition to the standard mobile apps Stanford University offers shuttle times, an event catalog, an online directory, and boasts a mobile learning research department, thereby giving students a chance to read case studies regarding mobile learning. The Stanford Mobile Inquiry Learning Environment program, allows students to use their devices to create, collaborate, and evaluate questions regarding educational topics, essentially becoming a research lab in students' pockets. At Florida International University, by means of one of its apps, offered to students the availability of library resources and access all video content [22], [23].

In addition, mobile applications have potential for helping students increase their physical activity, since little is known about the behavior change techniques via installed application, as recent research showed [24]. Furthermore, mobile apps have important use in psychological health inquiry. Study reveal results in which the installation of a specific application in a mobile phone provides a cognitive behavioral therapy intervention for the treatment of depression [25]. Lately, there is an increasing number of mobile apps available for adolescents with mental health problems and an increasing interest in assimilating mobile health into mental health services. Researchers have systematically searched for relevant publications, which describe mental health apps (targeting depression, bipolar disorder, anxiety disorders, self-harm, suicide prevention, conduct disorder, eating disorders and body image issues, schizophrenia, psychosis, and insomnia) for mobile devices for use by adolescents younger than 18 years [26]. 
Furthermore, there is a widely acceptable opinion that iPad applications are being used as an added tool for learning within educational environments improving the academic skills of students. A recent pilot study investigated the competence of iPad applications in improving the literacy and overall academic skills [27] .Results reveal that while statistical significance was not obtained, practical significance was found for the use of iPad applications to support learning in the literacy skill area of spelling knowledge and number concept. Also, the iPad applications that were chosen for this project were selected with several key criteria in mind and were mainly focused on the key academic concepts. Besides, they were developmentally appropriate for children with several levels of difficulty through which children could move independently, according to their needs and they provided positive or neutral feedback to children's responses. For the intervention condition, the applications gave multiple opportunities for the child to learn about and practice at least one of the skill areas [28].

Taking the above into consideration, many researchers have also focused on using mobile learning for assessing mathematic in secondary students. Firstly, K-Nect project, targets secondary at-risk students to focus on increasing their mathematics skills through mobile smartphones [29]. MobileMath, offers several methods to help students learn mathematical skills. Learners learn through learning by doing by practicing their skills in the games. The learners therefore engage in direct experience and focus on learning reflection to increase their knowledge, skills, and values. MobileMath uses various personalization rules for creating the recommendations for the learners, assisting them in choosing activities and making navigation easy. Also, consists of several features such as games, lessons, tutorials, examples and quizzes, which offer a different strategy for learning the topic. The algebra content is embedded into the game itself in a way that an algebraic skill is required for playing each game while there are games for finding factors, adding and subtracting directed numbers, factorization and solving equations [28].

\section{Supporting secondary students with Autism with Mobile Applications}

Autism spectrum disorder is a lifelong, neurodevelopmental condition that affects approximately $1 \%$ of students [30]. It is also characterized by core impairments in social reciprocity, social communication and flexibility, a constellation of associated difficulties, including problems with executive function, sensory sensitivity, emotional and behavioural regulation, language, motor control and eating [31]. In most European countries the majority of children diagnosed with autism attend mainstream school [32]. Studies and evidence from the empirical literature, suggests most of the children with autism face considerable challenges and difficulties in mainstream school settings. Many educational researches have shown that children with autism are at elevated risk of being bullied at school [33] for having emotional and behaviour problems [34], and for showing lower-than-expected academic attainment given their high IQ [35]. There appear to be substantial barriers to the successful integration of 
students with autism into mainstream schools, and a better understanding of these barriers is needed to promote inclusion [36].

Furthermore, high schools are large, complex environments that often face of lack cohesion. High school tends to be more impersonal, competitive and complicated than middle school [37]. Undoubtedly, high school teachers have few of opportunities to interact regarding all the students' needs. In a single day, a high school student may have seven different classes, with a different teacher and group of each peers. In addition, students in high school are expected to be independent in their academic functioning with greater demands on their planning and organizational skills [38]. Within educational environment, difficulties in the areas of social interaction and courses s' performance can put students with autism at risk for social and educational isolation [39]. Information and communication technologies (ICTs) have opened new ways to help students with autism especially in high school. These technologies allow creation of truly teaching models suitable for autism and offer clinicians and teachers different support to work with [40]. The enthusiasm surrounding the use of new technologies (e.g. smartphones, tablets) to support adolescents with autism may be due to the tension of children with autism for such devices. Screen-based technology use is a primary and preferred discretionary activity for the majority of adolescents with autism [41],[42]. Researchers found that $98 \%$ of the teens with autism surveyed spent approximately $5 \mathrm{~h}$ per day on a computer during summer months, primarily engaged in playing video games and surfing the web. A study that compared the screen-based technology use of adolescents with autism to their typical siblings, found that participants on the spectrum were heavier users [42] Information and communication technology-based interventions can be classified into three main categories. First, iPod and iPad apps aim to facilitate specific aspects of social life. Second, serious games can be described as 'digital games and equipment with an agenda of educational design. Finally, ICT interventions include the use of robots with students with autism [43]. Of course, beyond entertainment, the importance is found in educational software that, through mobile apps, can teach autistic students in main stream high school [44].

In the last five years there has also been growing interest in the use of mobile technology by children with autism. Study evaluate the use of a specific app with multiple prompt levels, indicating its potential to increase efficacy in completion of novel tasks and transitioning within and between tasks. Educational researchers also used standardized measurement tools to measure the efficacy of a mobile app as cognitive aid in a sample of high school students with autism, indicating positive initial outcomes. Reports on the use of mobile technology are also being published specifically to support social skills development [28]. Mobile apps also offer the opportunity to modify the educational environment, for example by eliminating or reducing information that might distract attention from the main task, and allowing children to work at their own pace. Multi-touch tablets have been found to be appealing for children with autism, resulting in benefits such as increased motivation, attention and learning compared to traditional methods. 


\section{Methodology of our Research}

\subsection{Purpose of our research}

The aim of our study was to investigate whether the performance of autistic students in high school can be improved with the mobile apps use with specific educational software.

\subsection{Main research question}

The main research question that we were concerned about, was whether mobile apps use allows cognitive access in all courses, targeting to entering the university.

\subsection{Data collection}

For the purposes of our research a small questionnaire was given to high school teachers on completing for the mobile apps educational results using by autistic students.

\subsection{Participants}

The survey involved on a group of high school teachers. Out of the 124 participants, 50 were men and 74 were women.

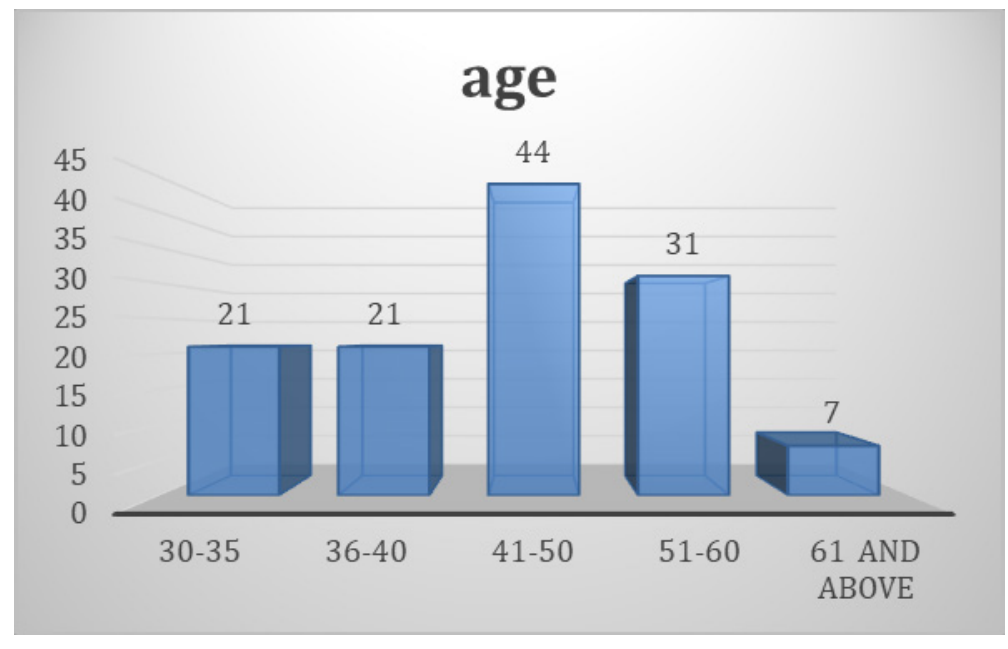

Fig. 1. Graph 1. Age of participants 


\section{training in ICTs}

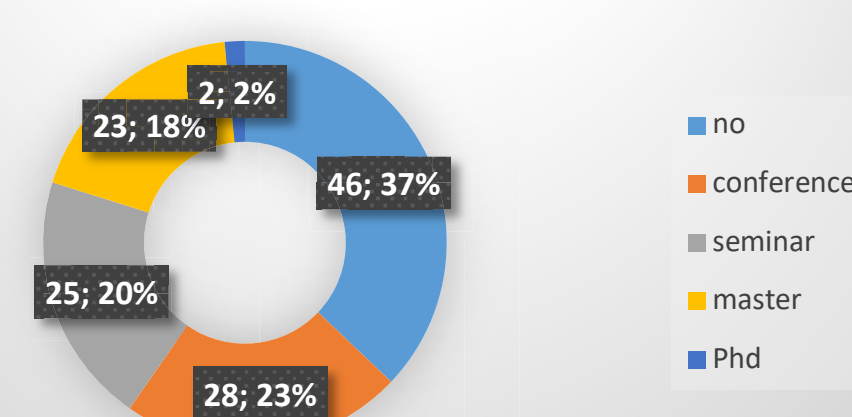

Fig. 2. Graph 2. Teachers training in ICTs

\subsection{Procedure}

We collected our data from February of 2018 to May of 2018 with 124 participants, who are educators in high schools in Athens. Moreover, to each participant was given an Android-based cell phone with an online structured questionnaire developed by us.

\subsection{Statistical analysis}

Statistical analysis of the data was carried out with the SPSS 23 statistical package. The frequency of teacher's age and teacher training in ICTs were calculated. We found the Correlations between all variables using the Pearson Chi-Square. Our results are presented in the form of text.

\subsection{Results}

Research question 1: Whether the age of teachers influence their views about using mobile apps by autistic students. 
Table 1.

\begin{tabular}{|c|c|c|c|c|c|}
\hline \multicolumn{2}{|c|}{} & \multicolumn{2}{|c|}{ Higher performance by using mobile apps } & \multirow{2}{*}{ Total } \\
\hline & $30-35$ & no & yes & $\begin{array}{c}\text { Depends on } \\
\text { the student }\end{array}$ & \\
\hline & $36-40$ & 3 & 5 & 13 & 21 \\
\hline & $41-50$ & 4 & 7 & 10 & 21 \\
\hline & $51-60$ & 10 & 18 & 25 & 44 \\
\hline & 61 and above & 4 & 8 & 13 & 31 \\
\hline
\end{tabular}

$X^{2}=41,759, \mathrm{df}=16, \mathrm{p}=0,000$

The value of the Pearson Correlation Coefficient between the variable 'index age" and the variable: "index higher performance by using mobile apps" were statistically significant

\section{Conclusion}

The purpose of our study was to examine how can the opportunity to high school students with autism to claim equal access to knowledge as do the other students be offered, by using supportive educational procedures, and especially mobile apps. In this effort 124 participants, who are educators in high school in Athens enrolled. Concerning the research questions, the results show an important correlation between the age of educators and their views about the digital education practice of autistic students. Especially, the 41-50 year old are more positive than their colleagues, and they also point out the capabilities of each student. In addition the data that concern teachers' response "depends on the student" especially correlated with teachers' ICTs training, are particularly important. In our research the majority of responses "depends on the student" which states the decisive role of the individual educational profile of each autistic student, plays a catalytic role.

Furthermore, well-designed mobile apps offer consistent and clearly defined tasks and visually cued instructions that can reduce misunderstandings caused by multiple verbal instructions [45] and thus promote independent educational functioning. In high schools, the complex academic environment can increase demands on organizational skills, planning skills and working memory for any student, but especially for students with autism. Recent developments in handheld devices with tools like portable checklists and reminder alarms can help increase independence in completing tasks [46]. In addition to previous research, this study revealed the educators 'views that high school students with autism may use mobile apps in a variety of supportive educational ways. In many studies, participants reported using technology apps in school to increase their independence, reduce their anxiety, and improve their social opportunities. They also reported bringing technology tools with them to school every day but entry find barriers to its use through school and classroom restrictions on technology use [47]. 


\section{References}

[1] Carrington, S. (1999). Inclusion needs a different school culture. International Journal of Inclusive Education, 3(2), 257-268, http://dx.doi.org/10.1080/136031199285039

[2] Skiba, R. J. (2002). Special Education and School Discipline: A Precarious Balance. Behavioral Disorders, 27 (2), 81-97, https://doi.org/10.1177/019874290202700209

[3] Smith, K.A., Sheppard, S.D., Johnson, D.W \&. Johnson, R.T. (2005). "Pedagogies of Engagement: Classroom-Based Practices. Journal of Engineering Education, 94(1),87-101 https://doi.org/10.1002/j.2168-9830.2005.tb00831.x

[4] Sharples, M., Taylor, J. \& Vavoula, G. (2013). A Theory of Learning for the Mobile Age:Learning through conversation and exploration across contexts. R. Andrews and C. Haythornthwaite. The Sage Handbook of E-learning Research, Sage publications, 221-247, https://telearn.archives-ouvertes.fr/hal-00190276

[5] Fu, F.-L., Su, R.-C. \& Yu,S.-C. (2009). 'E Game Flow: A scale to measure learners'enjoyment of e-learning games', Computers \& Education, 52(1), 101-112, http://www. sciencedirect.com/science/article/pii/S0360131508001024 https://doi.org/10.1016/j.comp edu.2008.07.004

[6] Melhuis.k. \& Falloon, G.(2010).Looking to the future:-M-Learning with the I-pad., 1-16

[7] Chu, H. C., Hwang, G. J., Tsai, C. C., \& Tseng, J. C. (2010). A two-tier test approach to developing location- aware mobile learning systems for natural science courses. Computers \& Education, 55(4), 1618-1627 https://doi.org/10.1016/j.compedu.2010.07.004

[8] Büyükbaykal,C. I. (2014). Communication Technologies and Education In the Information Age. Procedia - Social and Behavioral Science, 636-640

[9] Motamedi,V. \& Sumrall, W. J. (2000). Mastery learning and contemporary issues in education. Action in Teacher Education, 22(1), 32-42.

[10] Colis, B. \& Moonen, J. (2001). Flexible learning in a digital world: Experiences and expectations. London: Kogan-Page 10

[11] Litchfield, A. J., Dyson, L. E., Lawrence, E. M., \& Bachfischer, A. (2007). Directions for mlearning research to enhance active learning. In Annual Conference of the Australasian Society for Computers in Learning in Tertiary Education. Centre for Educational Development, Nanyang Technological University.

[12] Johnson, L., Adams Becker, S., Estrada, V., \& Freeman, A. (2014). NMC horizon report: 2014 higher education edition. Austin, Texas: The New Media Consortium.

[13] Vázquez-Cano, E. (2014). Mobile Distance Learning with Smartphones and Apps in Higher Education. Educational Sciences: Theory and Practice, v14 (4), pp1505-1520. Retrieved January 28, 2015, from http://files.eric.ed.gov/fulltext/EJ1045122.pdf https://doi.org/10 $.12738 /$ estp.2014.4.2012

[14] Hsu, Y. C., Rice, K., \& Dawley, L. (2012). Empowering educators with Google's Android App Inventor: An online workshop in mobile app design. British Journal of Educational Technology, 43, E1-E5. doi:10.1111/j.1467-8535.2011. 01241.x Johnson

[15] Stathopoulou,A., Karabatzaki,Z., Drigas, A. et al (2018). «Mobile assessment procedures for mental health and literacy skills in education». International Journal of Interactive Mobile Technologies, 12 (3), 21-36 https://doi.org/10.3991/ijim.v12i3.8038

[16] Kukulska-Hulme, A. (2009). Will mobile learning change language learning? ReCALL, 21(2), 157-165https://doi.org/10.1017/S0958344009000202

[17] Johnson, L., Smith, R., Willis, H., Levine, A., \& Haywood, K. (2011). The 2011 Horizon Report. Austin, Texas: The New Media Consortium.

[18] Barrs, K. (2011). Mobility in learning: The feasibility of encouraging language learning on smartphones. Studies in Self-Access Learning Journal, 2(3), 228-233 
[19] Alqahtani,M. \& Mohammad,H.(2015). Mobile Applications' Impact on Student Performance and Satisfaction. The Turkish Online Journal of Educational Technology,14 (4 ), $102-112$

[20] Vazquez-Cano,E. (2014). Mobile Distance Learning with Smartphones and Apps in Higher Education, Educational Sciences: Theory \& Practice, 14(4) , 1505-1520

[21] Johnson, D., Means, T., \& Khey, D. (2013). A State of flux: Results of a mobile device survey at the University of Florida. Educate Review online (May 6, 2013). Retrieved from http://www.educause.edu/ero/article/state-flux-results-mobiledevice-survey-universityflorida

[22] Johnson, L., Adams Becker, S., Estrada, V., \& Freeman, A. (2014). NMC horizon report: 2014 higher education edition. Austin, Texas: The New Media Consortium.

[23] Dahlstorm, E., Warraich, K. (2013). Student mobile computing practices, 2012: Lessons learned from Qatar (Research Report). Louisville, CO: EDUCASE Center for Applied Research. Retrieved from http://educase.edu/ecar

[24] Smith, J., J. Morgan,P., J.Plotnikoff, R., C.,Dally, K.,A., Salmon, J., Okely, A., D,. Finn, T., L. \& Lubans, D. R. (2014) Smart-Phone Obesity Prevention Trial for Adolescent Boys in Low-Income Communities: The ATLAS RCT, PEDIATRICS 134(3), 723-731 https://doi.org/10.1542/peds.2014-1012

[25] Watts, S., Mackenzie, A., Thomas, C., Griskaitis, A., Mewton, L., Williams, A.\& Andrews, G.(2013. CBT for depression: a pilot RCT comparing mobile phone vs. computer. BMC Psychiatry 13:49https://doi.org/10.1186/1471-244X-13-49

[26] Grist, R., Porter, J. \& Stallard, P. (2017). Mental Health Mobile Apps for Preadolescents and Adolescents: A Systematic Review, Journal of medical internet research, 19(5), 176 https://doi.org/10.2196/jmir.7332

[27] Hutchison, A., Beschorner, B., \& Schmidt-Crawford, D. (2012). Exploring the use of the $\mathrm{iPad}$ for literacy learning. The Reading Teacher, 66(1), 15-23. https://doi.org/1 $\underline{0.1002 / T R T R .01090}$

[28] Karabatzaki, Z., Stathopoulou, A., Drigas,A., et al ( 2018). «Mobile application tools for students in secondary education. An evaluation study». International Journal of Interactive Mobile Technologies. 12(2),142-161

[29] Franklin, T., \& Peng, L. W. (2008). Mobile math: Math educators and students engage in mobile learning. Journal of Computing in Higher Education, 20(2), 69-80 https://doi.org/10.1007/s12528-008-9005-0

[30] Baird G, Simonoff E, Pickles A, et al. (2006). Prevalence of disorders of the autism spectrum in a population cohort of children in South Thames: The Special Needs and Autism Project (SNAP). The Lancet 368(9531), 210-215 https://doi.org/10.1016/S01406736(06)69041-7

[31] American Psychiatric Association (APA) (2013). Diagnostic and Statistical Manual. 5th ed. Washington, DC: APA

[32] Department for Education (2012). Special Educational Needs in England. London: Department for Education

[33] Sterzing PR, Shattuck PT, Narendorf SC, et al. (2012). Bullying involvement and autism spectrum disorders: prevalence and correlates of bullying involvement among adolescents with an autism spectrum disorder. Archives of Pediatrics \& Adolescent Medicine 166(11), 1058-1064 https://doi.org/10.1001/archpediatrics.2012.790

[34] Kaat, A.J., Gadow, K.D. \& Lecavalier, L. (2013). Psychiatric symptom impairment in children with autism spectrum disorders. Journal of Abnormal Child Psychology 41(6), 959-969 https://doi.org/10.1007/s10802-013-9739-7 
[35] Jones CRG, Happé F, Golden H, et al. (2009). Reading and arithmetic in adolescents with autism spectrum disorders: peaks and dips in attainment. Neuropsychology 23(6), 718-728 https://doi.org/10.1037/a0016360

[36] Mandy, W., Murin, M., Baykaner, O., Staunton, S., Hellriegel, J., Anderson, S., \& Skuse, D. (2016). The transition from primary to secondary school in mainstream education for children with autism spectrum disorder. Autism: The International Journal of Research and Practice, 20, 5 -13 https://doi.org/10.1177/1362361314562616

[37] Corcoran, T., \& Silander, M. (2009). Instruction in high schools: The evidence and the challenge. The Future of Children, 19(1), 157-183 https://doi.org/10.1353/foc.0.0026

[38] Rosenthal, M., Lawson, R., Dixon, E., Wallace, G., Wills, M., Yerys, B., \& Kenworthy, L. (2013). Impairments in real-world executive function increase from childhood to adolescence in autism spectrum disorders. Neuropsychology, 27(1), 13-18 https://doi.org/10 $.1037 / \mathrm{a} 0031299$

[39] Humphrey, N., Lewis, S. (2008). 'Make me normal': The views and experiences of pupils on the autistic spectrum in mainstream secondary schools. Autism, 12(1), 23-46. https://doi.org/10.1177/1362361307085267

[40] Josman, N., Ben-Chaim, H., Friedrich, H. \& Weiss P. (2008). Effectiveness of virtual reality for teaching street-crossing skills to children and adolescents with autism. Int $\mathrm{j}$ Disabil 8 (7), 49-56 https://doi.org/10.1515/IJDHD.2008.7.1.49

[41] Kuo, M., Orsmond, G., Coster, W. et al. (2013) Media use among adolescents with autism spectrum disorder. Autism 18(8), 914-923 https://doi.org/10.1177/1362361313497832

[42] Mazurek MO, Shattuck PT, Wagner M. et al. (2012) Prevalenceand correlates of screenbased media use among youths with autism spectrum disorders. Journal of Autism and Developmental Disorders 42: 1757-1767 https://doi.org/10.1007/s10803-011-1413-8

[43] Grossard, C.,Palestra, G., Xavier, J., Chetouani, M.,Grynszpan,O., Cohen, D.(2018). ICT and autism care: state of the art. Current Opinion in Psychiatry: Child and Adolescent psychiatry, 31(6)474-783. doi: $10.1097 /$ YCO.00000000000004553

[44] Capo B and Orellana A (2011) Web 2.0 technologies for classroom instruction: high school teachers' perceptions and adoption factors. Quarterly Review of Distance Education 12(4), 235-253.

[45] Grynszpan O, Weiss PL, Perez-Diaz F. et al. (2014) Innovative technology-based interventions for autism spectrum disorders: a meta-analysis. Autism 18(4): 346-361. https://doi.org/10.1177/1362361313476767

[46] Palmen, A, Didden, R. \& Verhoeven, L. (2012) A personal digital assistant for improving independent transitioning in adolescents with high-functioning autism spectrum disorder. Developmental Neurorehabilitation 15(6), 401-413 https://doi.org/10.3109/17518423. 2012.701240

[47] Hedges, S.H., Odom, S.L., Hume, M. \& Sam, A (2017): Technology Use as a Support Tool by Secondary Students with Autism. Autism, 1-10, https://doi.org/10. $\underline{1177 / 1362361317717976}$

\section{$7 \quad$ Authors}

Agathi Stathopoulou is Partner of Institute of Informatics \& telecommunications, Net Media Lab-Brain \& Mind R\&D, N.C.S.R. "DEMOKRITOS" Department of Psychology. She is a teacher in Secondary Education with a specialization in Greek philology. She hold PhD in Stress Disorder \& Adolescent Psychology. She has participated in many educational seminars and conferences as a keynote speaker and as 
instructor. She has taught at the Department of Special Education of University of Athens and at the Department of Greek Literary of Democritus University of Thrace. She has written one book, and articles in scientific journals.

Zoe Karabatzaki is a School Advisor at the 21st Preschool Educational Region of Athens. She holds a Ph.D. on Educational Sciences (Special Education). She has participated in many educational seminars and conferences as a keynote speaker and as instructor. Furthermore, she has taken part in research programs that were supported by many universities of Greece. She has written two books, chapters in collective volumes, articles in scientific journals and educational notes. She has taught at the Department of Special Education of UTH (University of Thessaly), at the Department of Education and Early Childhood of UOA and the Department of Greek Literary of Democritus University of Thrace. She is also a scientific associate at Net Media Lab, Brain \& Mind R\&D of N.C.S.R. 'Demokritos'.

Dimosthenis Tsiros hold a MSc. in Special Education. He is teacher in secondary Education with a specialization in physic.

Spiridoyla katsantoni holds a PhD in Special Education. She has taken part in research projects and seminars. At the current period is serving as a special educator at the Center for Diagnosis, Differentiation and Support, where pupils with special educational needs are assessed. She is also a scientific associate at Net Media Lab, Brain \& Mind R\&D of N.C.S.R. 'Demokritos'

Athanasios Drigas is a director of research at N.C.S.R. Demokritos. He is the Coordinator and founder of Net Media Lab, Brain \& Mind R\&D since 1996. From 1985 to 1999 he was the Operational manager of the Greek Academic network. He has been the Coordinator of Several International Projects, in the fields of ICTs, and eservices (e-learning, e-psychology, e-government, e-inclusion, e-culture etc). He has published more than 300 articles, 7 books, 25 educational CD-ROMs and several patents. He has been a member of several International committees for the design and coordination of Network and ICT activities and of international conferences and journals. (e-mail: dr@iit.demokritos.gr).

Article submitted 22 October 2018. Resubmitted 02 January2019. Final acceptance 20 January 2019. Final version published as submitted by the authors. 